\title{
Cancer surgery induces inflammation, immunosuppression and neo-angiogenesis, but is it influenced by analgesics?
}

\section{[version 1; peer review: 3 approved]}

\author{
Patrice Forget ${ }^{1} 1$, Olivier Simonet ${ }^{2}$, Marc De Kock ${ }^{1}$ \\ ${ }^{1}$ Departments of Anesthesiology, Cliniques Universitaires Saint-Luc, Université Catholique de Louvain, Brussels, Belgium \\ ${ }^{2}$ Department of Anesthesiology, Centre Hospitalier Wallonie-Picarde, Tournai, B-7500, Belgium
}

V1 First published: 03 Apr 2013, 2:102

https://doi.org/10.12688/f1000research.2-102.v1

Latest published: $03 \mathrm{Apr}$ 2013, 2:102

https://doi.org/10.12688/f1000research.2-102.v1

\section{Abstract}

Surgery remains a main part of the treatment of most solid tumors. Paradoxically, rapid disease progression may be a consequence of surgery in patients presenting with a dysregulated inflammatory response, and increased angiogenesis consequent to a suppressed antitumoral immune response. Physicians taking care of cancer patients should be aware of the important findings that indicate that analgesic techniques could play a role in these phenomena.

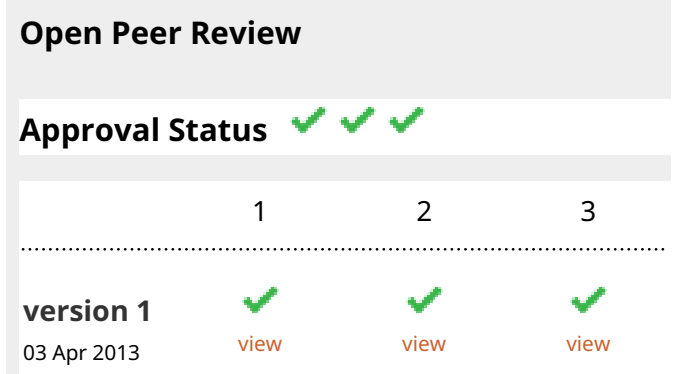

1. Alain Borgeat, Orthopedic University Hospital Balgrist, Zurich, Switzerland

2. Erxi Wu, North Dakota State University, Fargo, ND, USA

3. Dan Benhamou, Bicetre Hospital, Paris, France

Any reports and responses or comments on the article can be found at the end of the article.

Corresponding author: Patrice Forget (forgetpatrice@yahoo.fr)

Competing interests: No competing interests were disclosed.

Grant information: This work was exclusively supported by the Department of Anesthesiology of the Universite catholique de Louvain, St-Luc Hospital, Belgium.

The funders had no role in study design, data collection and analysis, decision to publish, or preparation of the manuscript.

Copyright: @ 2013 Forget P et al. This is an open access article distributed under the terms of the Creative Commons Attribution License, which permits unrestricted use, distribution, and reproduction in any medium, provided the original work is properly cited.

How to cite this article: Forget $P$, Simonet $O$ and De Kock $M$. Cancer surgery induces inflammation, immunosuppression and neoangiogenesis, but is it influenced by analgesics? [version 1; peer review: 3 approved] F1000Research 2013, 2:102

https://doi.org/10.12688/f1000research.2-102.v1

First published: 03 Apr 2013, 2:102 https://doi.org/10.12688/f1000research.2-102.v1 


\section{Introduction}

The natural history of cancer is a complex and rapidly evolving field. For example, in breast cancer, the growth of the primary tumor and the dissemination of neoplastic cells are linked, at least in part, to inflammation leading to immune dysfunction and an/or increased angiogenesis ${ }^{1,2}$. For breast cancer, as well as for most solid tumors, surgery remains a main part of the treatment. However, paradoxically, the surgical period, and the associated inflammatory reaction, is itself a high risk factor for the development of metastases and this phenomenon may be explained by the rapid release of inducers of angiogenesis concomitant to a profound immunosuppression ${ }^{1,2}$. One example, sometimes observed, is the rapid postoperative development of additional tumors and metastasis when a primary tumor is surgically removed ${ }^{2}$.

Other factors can accentuate this phenomenon, including the metabolic and hormonal changes that occur and are determined by the inflammatory/catecholaminergic "stress reaction" to surgery". To counteract these effects, perioperative physicians, including anesthesiologists, surgeons and oncologists, must help the patient to maintain homeostasis against the consequences of both cancer and tissular attrition. Anesthetic and analgesic techniques are one part of this strategy, but their effects, however important, are different and not well understood. Indeed, these drugs may influence immunity and tumor development, either directly by interfering with cellular mechanisms (e.g. cell apoptosis) or indirectly by interactions with the endocrine and sympathetic systems.

In this paper, we discuss the consequences of perioperative inflammation in cancer surgery on immunity and angiogenesis. Secondly, we describe why analgesic techniques may play a role in these phenomena.

\section{Perioperative inflammation-related immunosuppression and neoangiogenesis are seen in cancer patients at risk of relapse}

The early existence of dormant metastasis is matter of debate ${ }^{2}$. One argument is the kinetics observed in cancer recurrence after breast cancer surgery. Indeed, when analyzing the timing of the relapse of patients under endocrine therapy, recurrences occur gradually over the first 10 to 15 years. In contrast, in women not treated with endocrine therapy (i.e. with estrogen-receptor-negative tumors), the majority of cancer relapses occur in the first two years ${ }^{4}$. This suggests that these tumor cells have been maintained in a "dormant" state in the first group of women, whereas they may be present early in both groups ${ }^{5}$.

The risk for these patients in undergoing surgery is that rapid growth of these cells could be induced through perioperative inflammation. Indeed, following a surgical trauma, a great, but short-lasting, inflammation is correlated with a potent immune response that precedes a longer duration of immunosuppression ${ }^{1}$. The role of this immunosuppression is probably to minimize the intensity of the proinflammatory response, and reduce the risks of autoimmune disorders and/or necrosis of tissue ${ }^{6,7}$. Locally and throughout the body, the release of cytokines underlies the initiation, maintenance and regulation of the inflammatory response. After tissue injury, monocytes and macrophages rapidly release interleukin 1 (IL-1) and tumor necrosis factor alpha (TNF- $\alpha$ ). IL-1 stimulates and maintains the secretion of other cytokines such as interleukin 6 (IL-6) that are major mediators of the systemic effects of the stress response. The production of adrenocorticotropic hormone $(\mathrm{ACTH})$ and cortisol are stimulated and are regulated by a negative feedback system ${ }^{8}$.

The tissue damage caused by surgery is also likely to generate pain. This causes the secretion of endogenous opioids that provide analgesia of short duration by their peripheral and central effects 9 Peripherally, the presence of opioid receptors on immune cells allows $\beta$-endorphins to have a direct effect on the proliferation, migration and cytotoxicity of these cells ${ }^{9}$. Some neurotransmitters, including substance P, can interact with the pain pathways. At the central level, active pain regulatory mechanisms act via the periaqueductal gray matter of the midbrain and through the $\beta$-endorphin and catecholaminergic pathways. Norepinephrine inhibits natural killer (NK) cell activity via the $\beta-2$ receptor. The cholinergic system and the vagus nerve play a role that is often opposite to that of the sympathetic system ${ }^{10}$.

In turn, the brain monitors and controls these loops of inflammation. The hypothalamic-pituitary, cortex and cerebellum are involved in the control of lymphoid organs, especially the spleen and many adrenergic receptors are present on $\mathrm{B}$ and $\mathrm{T}$ lymphocytes, macrophages, neutrophils and NK cells. Finally, the endocrine system interacts with the brain, immune cells and most organs ${ }^{6,7}$. Glucocorticoids, for example, have anti-inflammatory properties but are essential for normal immune response. Prostaglandins and prostacyclin, particularly PGE2, are produced, among others, by dendritic cells and macrophages. They have a major role in the regulation of immunity in general and NK activity in particular. In addition, PGE2 plays a major role in the stimulation of epithelial cell proliferation, inhibition of apoptosis, production of mutagens and stimulation of angiogenesis ${ }^{11}$. This may explain the high incidence of overexpression of COX-2 in breast cancer, as in other cancers, and higher aggressiveness of these tumors ${ }^{11}$.

Neo-angiogenesis is probably a major step in the induction of growth of a dormant metastasis. Indeed, it appears that solid tumors cannot grow larger than $2-3 \mathrm{~mm}$ in diameter unless they induce their own blood supply ${ }^{12}$. The expression of the angiogenic phenotype, physiologically to promote wound healing, is a complex process that depends on a number of cellular and molecular events, including degradation of the surrounding basement membrane, migration of endothelial cells, cell proliferation, the formation of tube-like structures and the maturation of these endothelial-lined tubes into new blood vessels ${ }^{13}$.

As a consequence, most of the modifications in the immune system and the angiogenesis phenotype are linked to the degree of tissue injury and its consequent inflammation. The logical strategy is then to promote minimally invasive surgery that is designed to limit these impacts, to maintain homeostasis ${ }^{14}$ and reduce the stress response ${ }^{8}$. These arguments have led some authors to consider that minimally invasive procedures might be favorable in terms of immunity when compared with invasive procedures due to the need to manage other changes driven by the "secondary aggressions", i.e., hypothermia, hemorrhage, and psychological factors such as anxiety ${ }^{1}$. 


\section{Effect of analgesics on inflammation, anticancer immunity and angiogenesis}

A possible way to influence the perioperative inflammatory reaction and their consequences for immune cells and angiogenesis is by modifying analgesic techniques. This could have an important impact on patient outcome following surgery.

Macrophages, T lymphocytes, NK T and other cells and many cytokines are involved in the defense mechanisms of nonspecific immunity. Of these, the role of NK cells in defense against infection and the development of tumor cells ${ }^{1,15-17}$ has been largely demonstrated. The study of animal models has helped us to understand their role in the mechanisms behind perioperative anti-metastatic protection, but also their vulnerability ${ }^{16-18}$. In humans, a significant correlation between NK activity and patient prognosis is related to the development of metastases ${ }^{19}$. The strong depression of the cytotoxicity of the NK cells in the perioperative period may significantly alter the defense mechanisms of patients ${ }^{1}$.

Analgesic techniques that reduce the inflammatory response may be favorable in terms of immunity ${ }^{8}$. Recent data suggest that the analgesic techniques (intravenous opioids, non-steroidal anti-inflammatory drugs (NSAIDs) and locoregional analgesia) could have an impact on the long-term prognosis after cancer surgery ${ }^{20,21}$, including for breast cancer ${ }^{22,23}$. Opioids are the drugs most studied in the context of the perioperative immune response. In the absence of pain, morphine induces a decrease in NK activity ${ }^{25}$. It is not clear whether it is the opioids, but possibly also the withdrawal of opioid therapy, that is responsible for opioid-induced immunosuppression ${ }^{24}$. Nevertheless, pain itself induces a significant immune response. Because this response leads to a significant degree of immunosuppression, postoperative analgesia is, by itself, immunoprotective ${ }^{1}$. Morphine therefore allows the maintenance of NK activity and protection against metastasis in animal pain models ${ }^{25}$. In humans, similar arguments can be used to offer the lowest effective dose of opioid ${ }^{24}$. Data on synthetic opioids have revealed a similar phenomenon with fentanyl and sufentanil, probably mediated via the $\mu$-opioid receptor. Nevertheless, differences linked to selective $\mu 1$-activation by synthetic opioids, in contrast to $\mu 3$-activation by morphine, could explain the more favorable profile of morphine and may merit further investigation ${ }^{25}$. Opioids could also affect angiogenesis and the growth of tumors. In the perioperative period and after tissue injury, important angiogenic signals, including epithelial growth factors (VEGF), act via receptor tyrosine kinases and G-protein-coupled receptor (GPCR). This may have a major importance as morphine can transactivate these GPCR, increasing neo-angiogenesis ${ }^{13}$.

Prostaglandins are another major perioperative influence on immunity and angiogenesis and the promotion of tumor growth ${ }^{26}$. The data concerning the maintenance of NK activity by NSAIDs are encouraging, in some, but only a few human clinical studies. In a retrospective study, we showed that receiving ketorolac, a NSAID, just before surgery, was an independent factor associated with longer recurrence-free survival after breast cancer surgery ${ }^{22}$. These results may be explained by the fact that prostaglandin E2 (PGE2), released by monocytes and dendritic cells in order to regulate the inflammatory cascade, profoundly depresses cellular antitumoral immunity, i.e. NK activity ${ }^{27}$. This suppression of NK activity, and possibly an initial flare-up of angiogenesis, dissipates quickly after the removal of the prostaglandins. There may then be a short therapeutic window when NSAIDs may have a potent impact on the oncological outcome ${ }^{22}$.

It seems clear that regional anesthesia, particularly central blocks, are associated with anti-inflammatory effects, and allow the protection of anticancer immunity, including NK activity, after major surgery $^{28}$, but this effect has not been demonstrated after minor surgery ${ }^{29}$. It is possible that this effect is responsible for a lower incidence of recurrence after surgery for breast, colon or prostate cancers, however this is an unresolved debate due to poor methodology and lack of perioperative immune monitoring $20,21,23,30-33$.

Anesthesiologists are using many other drugs that are not necessarily associated with analgesic effects. Data are sparse and mostly inconclusive concerning barbiturates, halogenated gases, propofol and etomidate. It seems likely that ketamine, a widely used co-analgesic, has a dose-dependent effect, being protective at low doses during a painful stimulus and potentially harmful at high doses in the absence of surgery ${ }^{24}$. One interesting topic is the potential protective role of alpha-2-agonists, such as clonidine, typically used as co-analgesic during surgery on perioperative NK activity $^{24}$.

Is it time to change our pain management practices?

A goal of optimal control of pain may appear to be obvious, but it still remains a major concern for perioperative physicians. The quality of analgesia is facilitated by combinations of molecules (NSAIDs and anti-hyperalgesics such as ketamine) and techniques (intravenous, locoregional with local anesthetics). At this time, it is not clear whether these techniques may improve oncological outcome alone, indirectly by the avoidance of opioids, or both. Nevertheless, they improve pain management, postoperative rehabilitation and the prognosis for patients. These reasons remain the main argument to recommend such analgesic approaches before definitive conclusions on their influence on the oncological outcome $e^{8,14}$.

Moreover, it appears that high doses of opioids are carriers of longterm side effects that are probably underestimated (including opioid-induced hyperalgesia). The study of the role opioids play in the increase in angiogenesis and postoperative immunosuppression is of particular importance in oncological surgery, knowing that NK activity could be a prognostic criterion ${ }^{13,19}$. Taking into account that they improve pain management, it is appropriate to propose opioidsparing strategies, such as locoregional techniques and sympathetic modulation using intravenous $\alpha-2$ agonists ${ }^{24}$.

\section{Conclusions}

Understanding cancer development mechanisms is a major goal of clinical research and may lead to the development of strategies to counter the multiple factors involved in cancer pathology. It is very important to study all aspects of the problem, permitting the development of strategies associated with a higher long term survival after cancer surgery. The data available already affirm that the immune system and the angiogenesis phenotype play key roles in anticancer defenses, that the potential influence of surgery-related inflammation is large and that the effects of drugs and the techniques 
of analgesia may be important. Perioperative physicians must be aware that an optimal analgesic strategy may have along-term impact on patient outcome.

\section{Author contributions}

$\mathrm{PF}$ and MDK contributed to the design, the selection of the literature and the redaction of the manuscript. OS contributed to the redaction of the manuscript and was the scientific/medical advisor.

\section{Competing interests}

No competing interests were disclosed.

\section{Grant information}

This work was exclusively supported by the Department of Anesthesiology of the Université catholique de Louvain, St-Luc Hospital, Belgium.

The funders had no role in study design, data collection and analysis, decision to publish, or preparation of the manuscript.
1. Shakhar G, Ben-Eliyahu S: Potential prophylactic measures against postoperative immunosuppression: Could they reduce recurrence rates in oncological patients? Ann Surg Oncol. 2003; 10(8): 972-92. PubMed Abstract | Publisher Full Text

2. Retsky M, Demicheli R, Hrushesky W, et al.: Surgery triggers outgrowth of laten distant disease in breast cancer: an inconvenient truth? Cancers. 2010; 2(2): 305-337. Publisher Full Text

3. Wrona D: Neural-immune interactions: An integrative view of the bidirectional relationship between the brain and immune systems. J Neuroimmunol. 2006; 172(1-2): 38-58 PubMed Abstract | Publisher Full Text

4. Stanojević-Bakić N, Vucković-Dekić L, Radomirović S, et al.: The influence of surgery and anesthesia on lymphocyte functions in breast cancer patients: in vitro effects of indomethacin. Neoplasma. 1999; 46(1): 54-60. PubMed Abstract

5. Mansell J, Monypenny IJ, Skene Al, et al.: Patterns and predictors of early recurrence in postmenopausal women with estrogen receptor-positive early breast cancer. Breast Cancer Res Treat. 2009; 117(1): 91-98. PubMed Abstract | Publisher Full Text

6. Elenkov IJ, Wilders RL, Chrousos GP, et al.: The sympathetic nerve - An integrative interface between two supersystems: The brain and the immune system. Pharmacol Rev. 2000; 52(4): 595-638.

PubMed Abstract

7. Viswanathan K, Daugherty C, Dhabhar FS: Stress as an endogenous adjuvant: augmentation of the immunization phase of cell-mediated immunity. Int Immunol. 2005; 17(8): 1059-69.

PubMed Abstract| Publisher Full Text

8. Desborough JP: The stress response to trauma and surgery. $\mathrm{Br} J$ Anaesth. 2000; 85(1): 109-17.

PubMed Abstract | Publisher Full Text

9. Schaffer M, Beiter T, Becker HD, et al:: Neuropeptides: mediators of inflammation and tissue repair? Arch Surg. 1998; 133(10): 1107-16. PubMed Abstract | Publisher Full Text

10. Panerai AE, Sacerdote $P$ : Beta-endorphin in the immune system: a role at last? Immunol Today. 1997; 18(7): 317-9.

PubMed Abstract | Publisher Full Text

11. Singh B, Lucci A: Role of cyclooxygenase-2 in breast cancer. J Surg Res. 2002; 108(1): 173-9.

PubMed Abstract

12. Folkman J, Szabo S, Stovroff M, et al.: Duodenal ulcer. Discovery of a new mechanism and development of angiogenic therapy that accelerates healing Ann Surg. 1991; 214(4): 414-425. PubMed Abstract | Free Full Text

13. Singleton PA, Lingen MW, Fekete MJ, et al.: Methylnaltrexone inhibits opiate and VEGF-induced angiogenesis: role of receptor transactivation. Microvasc Res. 2006; 72(1-2): 3-11.

PubMed Abstract | Publisher Full Text

14. Kehlet $\mathrm{H}$ : Multimodal approach to control postoperative pathophysiology and rehabilitation. Br J Anaesth. 1997; 78(5): 606-17.

PubMed Abstract | Publisher Full Text

15. Curtis JL, Punturieri A: Enhancing antitumor immunity perioperatively: a matter of timing, cooperation, and specificity. Am J Respir Cell Mol Biol. 2003; 28(5):

$541-5$.

PubMed Abstract | Publisher Full Text | Free Full Text

16. Forget $\mathrm{P}$, Collet $\mathrm{V}$, Lavand'homme $\mathrm{P}$, et al:: Does analgesia and condition influence immunity after surgery? Effects of fentanyl, ketamine and clonidine on natural killer activity at different ages. Eur J Anaesthesiol. 2010; 27(3): 233-40.

PubMed Abstract | Publisher Full Text

17. Page GG, McDonald JS, Ben-Eliyahu S: Pre-operative versus postoperative administration of morphine: impact on the neuroendocrine, behavioural, and metastatic-enhancing effects of surgery. Br J Anaesth. 1998; 81(2): 216-23. PubMed Abstract | Publisher Full Text

18. Bar-Yosef S, Melamed R, Page GG, et al:: Attenuation of the tumor-promoting effect of surgery by spinal blockade in rats. Anesthesiology. 2001; 94 (6): 1066-73.

PubMed Abstract | Publisher Full Text

19. Liljefors M, Nilsson B, Hjelm Skog AL, et al.: Natural killer (NK) cell function is a strong prognostic factor in colorectal carcinoma patients treated with the monoclonal antibody 17-1A. Int J Cancer. 2003; 105(5): 717-23. PubMed Abstract | Publisher Full Text

20. Biki B, Mascha E, Moriarty DC, et al:: Anesthetic technique for radical prostatectomy surgery affects cancer recurrence: a retrospective analysis. Anesthesiology. 2008; 109(2): 180-7.

PubMed Abstract | Publisher Full Text

21. Christopherson R, James KE, Tableman M, et al.: Long-term survival after colon cancer surgery: a variation associated with choice of anesthesia. Anesth Analg. 2008; 107(1): 325-32.

PubMed Abstract | Publisher Full Text

22. Forget $\mathrm{P}$, Vandenhende $\mathrm{J}$, Berliere $\mathrm{M}$, et al:: Do intraoperative analgesics influence breast cancer recurrence after mastectomy? A retrospective analysis. Anesth Analg. 2010; 110(6): 1630-1635.

PubMed Abstract | Publisher Full Text

23. Exadaktylos AK, Buggy DJ, Moriarty DC, et al:: Can anesthetic technique for primary breast cancer surgery affect recurrence or metastasis? Anesthesiology. 2006; 105(4): 660-4.

PubMed Abstract | Publisher Full Text | Free Full Text

24. Forget $\mathrm{P}, \mathrm{De}$ Kock $\mathrm{M}$ : [Could anaesthesia, analgesia and sympathetic modulation affect neoplasic recurrence after surgery ? A systematic review centred over the modulation of natural killer cells activity]. Ann Fr Anesth Reanim. 2009; 28(9): 751-68.

PubMed Abstract | Publisher Full Text

25. Stefano GB, Kream RM, Mantione KJ, et al:: Endogenous morphine/nitric oxidecoupled regulation of cellular physiology and gene expression: implications for cancer biology. Semin Cancer Biol. 2008; 18(3): 199-210. PubMed Abstract | Publisher Full Text | Free Full Text

26. Walker W, Rotondo D: Prostaglandin E2 is a potent regulator of interleukin-12 and interleukin-18-induced natural killer cell interferon-gamma synthesis. Immunology. 2004; 111(3): 298-305. PubMed Abstract | Publisher Full Text | Free Full Text

27. Yakar I, Melamed R, Shakhar G, et al.: Prostaglandin e(2) suppresses NK activity in vivo and promotes postoperative tumor metastasis in rats. Ann Surg Oncol. 2003; 10(4): 469-79.

PubMed Abstract | Publisher Full Text 
28. Koltun WA, Bloomer MM, Tilberg AF, et al.: Awake epidural anesthesia is associated with improved natural killer cell cytotoxicity and a reduced stress response. Am J Surg. 1996; 171(1): 68-72.

PubMed Abstract | Publisher Full Text

29. Tøonnesen E, Huttel MS, Christensen NJ: Natural killer cell activity in patients undergoing minor gynaecological surgery. Eur $J$ Anaesthesiol. 1987; 4(2): 119-25.

PubMed Abstract

30. Gottschalk A, Ford JG, Regelin CC, et al:: Association between epidural analgesia and cancer recurrence after colorectal cancer surgery. Anesthesiology. 2010; 113(1): 27-34.

PubMed Abstract | Publisher Full Text
31. Tsui BC, Rashiq S, Schopflocher D, et al.: Epidural anesthesia and cancer recurrence rates after radical prostatectomy. Can J Anaesth. 2010; 57(2): 107-12.

PubMed Abstract | Publisher Full Text

32. Forget $\mathrm{P}$, Leonard D, Kartheuser A, et al.: Choice of Endpoint and Not Reporting All the Analgesics Used May Render Inconclusive Studies on Oncological Outcome. Anesthesiology. 2011; 114(3): 717.

PubMed Abstract | Publisher Full Text

33. Forget $\mathrm{P}$, Tombal $\mathrm{B}$, Scholtès $\mathrm{JL}$, et al:: Do intraoperative analgesics influence oncological outcomes after radical prostatectomy for prostate cancer? Eur Anaesthesiol. 2011; 28(12): 830-5.

PubMed Abstract 


\section{Open Peer Review}

\section{Current Peer Review Status:}

\section{Version 1}

Reviewer Report 09 May 2013

https://doi.org/10.5256/f1000research.1280.r938

(C) 2013 Benhamou D. This is an open access peer review report distributed under the terms of the Creative Commons Attribution License, which permits unrestricted use, distribution, and reproduction in any medium, provided the original work is properly cited.

\section{Dan Benhamou}

Bicetre Hospital, Paris, France

To the Editor,

First, note that it is extremely difficult to write detailed comments as lines are not numbered. Please modify the text to facilitate reviewers' work.

This is a nice review of the role of analgesia on postoperative outcome after cancer surgery. As stated by the authors, we still need confirmatory data and the present status of our knowledge only suggests a speculative effect, even if most studies concur to suggest a beneficial effect of a well-performed postoperative analgesia. It would also be important to note that all additional factors of a well-performed anesthesia (i.e. avoidance of hypotension or of hypothermia, treatment of anemia, prevention of hyperglycemia...) may also be factors that could improve postoperative outcome after cancer surgery.

That said, the reviewer has several minor comments to add:

Page 2, 2nd column, L12 of 1st paragraph: is instead of are (the subject of the sentence is "The production of...")

Page 2, 2nd column, L2 of 3rd paragraph: hypothalamic-hypopituitary complex/system/unit/axis... (choose one word)

Page 3, 1st column, L9 of 2nd paragraph: add "reduced"? (...with invasive procedures due to the reduced need...)

Page 3, 1st column, L1 of 5th paragraph: in this sentence and all along the text, use "regional" instead of "locoregional"

Page 3, 1st column, L10 and following lines of 5th paragraph: paragraph unclear: reorganize sentences to present first the beneficial effects of opioids (reduced pain) and then their harmful effects to facilitate reading

Page 3, 2nd column, L3 of 3rd paragraph: what do the authors mean by "protection of anticancer immunity"?

Page 4, 1st column, L10 of 2nd paragraph: it appears somewhat surprising that alpha-2 agonists are promoted with some apparent strength given the fact that our knowledge on these drugs in 
this context are not better that for other agents. Please modify the sentence to attenuate the strength of this recommendation.

Competing Interests: No competing interests were disclosed.

\section{I confirm that I have read this submission and believe that I have an appropriate level of} expertise to confirm that it is of an acceptable scientific standard.

Reviewer Report 07 May 2013

https://doi.org/10.5256/f1000research.1280.r914

(C) $2013 \mathrm{Wu}$ E. This is an open access peer review report distributed under the terms of the Creative Commons Attribution License, which permits unrestricted use, distribution, and reproduction in any medium, provided the original work is properly cited.

\section{Erxi Wu}

North Dakota State University, Fargo, ND, USA

This is an interesting research topic. It describes that cancer surgery induces inflammation, immunosuppression, and angiogenesis. Also these phenomena can be influenced by analgesics. As we know, Galen (Aelius Galenus) removed some tumours surgically, but he generally believed that cancer was best left untreated. The underlying mechanisms were not clear then. The research community can benefit from this well-written paper as this paper has updated the information for this topic.

This paper can be improved if the mechanisms would have been discussed in depth. After cancer surgery, HIF-1 alpha and MMPs may also be up-regulated. This paper has not mentioned them. Thus, it would be helpful if authors search and study more literature.

I have simply searched some literature, I think the following papers should be cited:

Tavare AN et al. Cancer recurrence after surgery: direct and indirect effects of anesthetic agents. Int J Cancer. 2012 doi: 10.1002/ijc.26448

Retsky M et al. NSAID analgesic ketorolac used perioperatively may suppress early breast cancer relapse: particular relevance to triple negative subgroup. Breast Cancer Res Treat. 2012 doi:

10.1007/s10549-012-2094-5

Deegan CA et al. Anesthetic technique and the cytokine and matrix metalloproteinase response to primary breast cancer surgery. Reg Anesth Pain Med. 2010 doi: 10.1097/AAP.0b013e3181 ef4d05

Thaker PH et al. Chronic stress promotes tumor growth and angiogenesis in a mouse model of ovarian carcinoma. Nat Med. 2006 doi: 10.1038/nm1447

Competing Interests: No competing interests were disclosed. 


\section{I confirm that I have read this submission and believe that I have an appropriate level of expertise to confirm that it is of an acceptable scientific standard.}

Reviewer Report 08 April 2013

https://doi.org/10.5256/f1000research.1280.r879

(C) 2013 Borgeat A. This is an open access peer review report distributed under the terms of the Creative Commons Attribution License, which permits unrestricted use, distribution, and reproduction in any medium, provided the original work is properly cited.
Alain Borgeat
Orthopedic University Hospital Balgrist, Zurich, Switzerland
There are more and more clues that inflammation, immune system and cancer recurrence may be directly associated. Therefore, this manuscript is very actual. It is well constructed and raises basic questions concerning the expected future adaptations of the management of the perioperative period.
Competing Interests: No competing interests were disclosed.
I confirm that I have read this submission and believe that I have an appropriate level of expertise to confirm that it is of an acceptable scientific standard.

The benefits of publishing with F1000Research:

- Your article is published within days, with no editorial bias

- You can publish traditional articles, null/negative results, case reports, data notes and more

- The peer review process is transparent and collaborative

- Your article is indexed in PubMed after passing peer review

- Dedicated customer support at every stage

For pre-submission enquiries, contact research@f1000.com 